\title{
Superior QRS axis in ventricular septal defect
}

\author{
N J SHAW, * M J GODMAN, * A HAYES, $\dagger$ G R SUTHERLAND $\dagger$ \\ From the Royal Hospital for Sick Children, Edinburgh, and †Southampton General Hospital, Southampton
}

SUMMARY The relation between the superior orientation of the QRS axis and the anatomical site of the defect in the ventricular septum in patients with a ventricular septal defect was studied. Of 1031 patients with a ventricular septal defect, $64(6.2 \%)$ had a superior axis on their electrocardiogram. In $59 \%$ of these patients the defect was in the inlet portion of the ventricular septum or affected this area. None of the cases was classified as an isolated ventricular septal defect of the persistent atrioventricular canal type.

While there is an association between a superior axis and perimembranous inlet ventricular septal defect, a superior QRS axis does not characterise a ventricular septal defect as being of the atrioventricular canal type.

Superior orientation of the QRS axis was seen in $15 \%$ of patients with the clinical features of a ventricular septal defect ${ }^{1}$ and this feature is claimed by some to characterise the site of the defect as likely to be in the posterior or inlet part of the septum. ${ }^{2}$ More specifically, it has been suggested that a superior QRS axis is particularly associated with isolated ventricular septal defects of the "atrioventricular canal type". ${ }^{2-}$

There is difficulty in determining with certainty from these earlier reports whether the ventricular septal defects referred to were truly of the "atrioventricular canal type"-if they were, the high incidence of left axis deviation is not unexpected. On the other hand, Anderson et al have suggested that these defects are more correctly termed perimembranous inlet ventricular septal defects.

We studied the relation between superior orientation of the QRS axis and the anatomical site of the defect in the ventricular septum in patients with a ventricular septal defect to see whether a ventricular septal defect associated with a superior axis was likely to be of the "atrioventricular canal type".

\section{Patients and methods}

One thousand and thirty one electrocardiograms of patients diagnosed as having an isolated ventricular septal defect who had attended the Department of

Requests for reprints to Dr M J Godman, Cardiology Department, Royal Hospital for Sick Children, Sciennes Road, Edinburgh EH9 1LF.

Accepted for publication 20 April 1989
Cardiology at the Royal Hospital for Sick Children, Edinburgh, and the Paediatric Cardiology Unit, Southampton General Hospital, from 1970 to 1986 were reviewed. Those having an axis of $-1^{\circ}$ to $-180^{\circ}$ were defined as having a superior orientation of the QRS axis. ${ }^{67}$

In those with a superior axis, cross sectional echocardiography, Doppler studies, previous angiograms, or previous operation notes were used to identify the anatomical site of each ventricular septal defect. The classification of ventricular septal defects was based on that proposed by Soto et $a l^{8}$ and modified by Sutherland et al for the echocardiographic diagnosis of ventricular septal defects. ${ }^{9}$ The angiographic differentiation of types of ventricular septal defects was as proposed by the Birmingham Alabama Group, which showed that with axial views an experienced angiographer can define the location, size, and relations of ventricular septal defects with high accuracy. ${ }^{1011}$

\section{Results}

Sixty four patients $(6 \cdot 2 \%)$ had a superior axis on their electrocardiogram, and this ranged from $-10^{\circ}$ to $-100^{\circ}$. We were able to study 59 of these patients.

In 25 patients the site of the ventricular septal defect was identified by cross sectional echocardiography together with inspection of previous angiograms or operation notes and in 27 the site was identified by review of previous angiograms or operation notes or both. The remaining seven had normal cross sectional echocardiograms with no defect visualised nor any feature that identified a defect as having been present and subsequently 
undergone spontaneous closure. A muscular ventricular septal defect was confirmed in three of these seven cases by Doppler study and in the remaining four a muscular ventricular septal defect was assumed to have been present because of the quality and site of the murmur previously heard on auscultation.

The table shows the distribution of defects by site in those patients with a superior axis on their electrocardiogram. In one patient, in whom only angiographic studies were available, the defect was seen in the perimembranous region but it was impossible to define its extent because of the poor quality of the angiographic films.

In three of the 32 patients who had cross sectional echocardiography the defect had closed by the time of examination. In a further 11, all with an inlet component to the defect, there was tricuspid valve tissue adhering to the margins of the defect; in all these patients the clinical course suggested this may have been a mechanism by which the defect had become smaller. In 34 of the 59 patients with a ventricular septal defect and superior axis (shown in the table) the defect was in or affected the inlet septum and in 24 patients it did not $\left(\chi^{2}=14.30\right.$ $\mathrm{p}<0.001$ ).

\section{Discussion}

We found that $65(6.2 \%)$ of 1031 patients with a ventricular septal defect had a superior orientation of the QRS axis on their electrocardiogram; but Pryor and Blount found this feature in $15 \%$ of patients with a ventricular septal defect. ${ }^{1}$ In $59 \%$ (35 of the 59 patients (table) of those with a superior orientation of the QRS axis the defect was in the inlet portion of the ventricular septum or affected this area; this includes one patient whose perimembranous defect was not clearly defined although it seemed to extend into the

Table Distribution of ventricular septal defect by site in patients with superior orientation of the $Q R S$ axis

\begin{tabular}{lr}
\hline Site & Number \\
\hline Perimembranous confluent & 16 \\
Perimembranous confluent + muscular & 1 \\
Perimembranous (extent not known) & 1 \\
Perimembranous confluent + muscular + gerbode & 1 \\
Perimembranous inlet & 15 \\
Perimembranous inlet + apical trabecular + muscular & 1 \\
$\quad$ inlet & 7 \\
Perimembranous outlet & 1 \\
Perimembranous outlet + muscular inlet & 4 \\
Muscular inlet & 1 \\
Muscular outlet & 10 \\
Gerbode & 1 \\
Total & 59 \\
\hline
\end{tabular}

inlet septum. In a previous study of 280 children with ventricular septal defects who were classified without reference to the orientation of the QRS axis only $29 \%$ had a defect affecting or in the inlet portion of the septum. ${ }^{9}$ Our findings therefore suggest that in patients with a ventricular septal defect who have a superior QRS axis the defect is most likely to lie in or affect the inlet portion of the ventricular septum $\left(\chi^{2}=14.30, \mathrm{p}<0.001\right)$. This is perhaps not surprising in view of the proximity of the penetrating bundle of the atrioventricular conduction tissues to the inlet portion of the septum and the position of the branching bundle between the membranous and muscular septa.

On the other hand, our study also indicated that the inlet ventricular septum is not affected in $41 \%$ of those patients with a ventricular septal defect who have superior orientation of the QRS axis. In these patients the ventricular septal defect lay in various sites in the perimembranous or muscular septum, although none was associated with a doubly committed subarterial defect. The mechanism by which the superior axis is produced in those patients is speculative. Sharrat and Virmani found left axis deviation in about $1 \%$ in normal children ${ }^{12}$ and Shinebourne et al found it in $1.6 \%$ of patients with acyanotic heart disease other than that caused by an atrioventricular canal. ${ }^{6}$ Fox et al reported left axis deviation in $40 \%$ of patients with multiple ventricular septal defects but did not describe the site of the defects in these patients nor were they able to offer any clear explanation for the high frequency of left axis deviation that they found. ${ }^{13}$

None of the patients was classified as having an isolated ventricular septal defect of the persistent atrioventricular canal type. Neufeld et al described 15 patients with a ventricular septal defect in whom the defect appeared to occupy a position similar to that of the ventricular component of a persistent common atrioventricular canal. ${ }^{2}$ In all 15 patients the electrocardiographic findings were striking in that the mean QRS axis lay above the isoelectric point. Their's was a necropsy study with $15(5 \%)$ of 300 ventricular septal defects being classified as the atrioventricular canal type.

It might seem surprising therefore that we did not identify any defects of the type reported by Neufeld et al. This difference may be apparent rather than real. Anderson et al suggested that the term "atrioventricular canal type of ventricular septal defect" is confusing, particularly when used to describe defects that they believe are more correctly termed "perimembranous inlet ventricular septal defects." They emphasise that the defects often referred to in published reports as isolated ventricular septal defects of the atrioventricular type 
have none of the characteristics of the anomalies grouped together as atrioventricular septal defects.

We accept that some perimembranous inlet defects show the signs of atrioventricular defects, but no patient in our study had such features and we agree with the opinion that "isolated atrioventricular canal defect" is rare (Soto et al, ${ }^{8}$ Becker and Anderson ${ }^{14}$ ).

A superior QRS axis therefore does not characterise a ventricular septal defect as being of the atrioventricular canal type. While there is an association between a superior axis and perimembranous inlet ventricular septal defect, almost half of all patients with such an axis will have the defect at a site other than the perimembranous inlet septum.

\section{References}

1 Pryor R, Blount SG. The clinical significance of true left axis deviation. Am Heart $J$ 1966;72:391-413.

2 Neufeld HN, Titus JL, DuShane JW, Burchell HB, Edwards JE. Isolated ventricular septal defects of the persistent common atrioventricular canal type. Circulation 1961;23:685-96.

3 Perloff JK, Roberts NK, Cabeen WR Jr. Left axis deviation. Circulation 1979;60:12-21.

4 Toscana-Barbosa E, Brandenburg RO, Burchell HB. Electrocardiographic studies of cases with intracardiac malformations of the atrioventricular canal. Mayo Clin Proc 1956;31:513-23.
5 Anderson RH, Becker AE, Lucchese FE, Meier MA, Rigby ML, Soto B. Morphology of congenital heart disease. Kent: Castle House Publications, 1983:23-35.

6 Shinebourne EA, Haworth SG, Anderson RH, Ulgur A. Differential diagnosis of congenital heart disease in the first three months of life. Arch Dis Child 1974;49:729-33.

7 Liebman J, Nada AS. An abnormally superior vector (formerly called marked left axis deviation). Am J Cardiol 1971;27:577-80.

8 Soto B, Becker AE, Moulaert AJ, Lie JT, Anderson RH. Classification of ventricular septal defects. $B r$ Heart $J$ 1980;43:332-43.

9 Sutherland GR, Godman MJ, Smallhorn JF, Guiterras P, Anderson RH, Hunter S. Ventricular septal defects. Two dimensional echocardiographic and morphological correlations. Br Heart $J$ 1982;47: 316-28.

10 Elliot LP, Bargeron LM, Soto B, Brown BR. Axial cine angiography in congenital heart disease. Radiol Clin North Am 1980;18:515-23.

11 Santamaria H, Soto B, Ceballos R, Bargeron LM, Coghlan HC, Kirklin JW. Angiographic differentiation of types of ventricular septal defects. Am J Roentgenol 1983;141:273-81.

12 Sharrat GP, Virmani S. Left axis deviation in otherwise healthy children. Pediatr Cardiol 1985;6:7-10.

13 Fox KM, Patel GR, Graham GR, et al. Multiple and single ventricular septal defect-a clinical and haemodynamic comparison. Br Heart J 1978;40: 141-6.

14 Becker AE, Anderson RH. Pathology of congenital heart disease. (Postgraduate pathology series.) Butterworths, 1981:93-117. 